\title{
Synthesis of Recursive Digital Filters with Finite Word Length: Problems and their Solutions
}

\author{
V.A. Lesnikov ${ }^{1}$, T.V. Naumovich ${ }^{2}$, A.V. Chastikov ${ }^{3}$ \\ Vyatka State University, Kirov \\ 17Vladislav.Lesnikov.ru@ieee.org, ${ }^{2}$ ntv_new@mail.ru, ${ }^{3}$ alchast@mail.ru
}

\begin{abstract}
Design of recursive digital filters involves sequential execution of the stages of functional and structural synthesis. At the stage of functional synthesis, the zeros and poles of the transfer function are calculated, which satisfy the specification of the requirements for the characteristics of the filter. At the stage of structural synthesis, a block diagram is formed. At this stage, the calculation of the structure coefficients (parametric synthesis) and the quantization of coefficients are performed. With the traditional approach at the stage of functional synthesis, the effects of the finite word length are not taken into account. At the same time, the stage of structural synthesis leads to distortion of the exact value of the coefficients of the digital filter, distortion of the zeros and poles of the digital filter, distortion of the transfer function, and frequency response. Therefore, it is necessary to either increase the bit depth or change the structural scheme. Despite a large number of publications describing the various structures, their applications are limited by the unique calculation method for each structure and by the extremely short range of the structures offered in available developed systems. This paper is an analytical report, which describes a new approach to the synthesis of recursive digital filters with finite word length. Based on the studied number-theoretic nature of zeros and poles of the digital filters with limited word length, it is proposed to finally compute the zeros and poles of the digital filters at the stage of functional synthesis, considering the limitations on the length of the words. The next step of structural synthesis will not distort the results of functional synthesis. The completed studies have shown the connection between the structure of the digital filters and the number-theoretic nature of zeros and poles. It is proposed to generate structural schemes by this nature, based on the revealed algebraic features of the matrix description of structures.
\end{abstract}

Keywords - IIR digital filter, finite word length, algebraic numbers, quantization of coefficients, $z$-plane discretization, z-plane topography, topological matrix

\section{INTRODUCTION}

Despite the long history [1] - [3], the problem of the synthesis of recursive digital filters, taking into account the finite digit capacity of the numbers involved in the calculations, is far from the final solution. If one does not take into account the finite accuracy of calculations, the synthesis of recursive filters is well studied, described and implemented in development systems [4] - [6].
In the absence of stringent requirements for the characteristics of the digital filter, the problem of synthesis and realization is rather simply solved, and under the condition of limited capacity. With the complication of the requirements for the characteristics of the digital filter, a large number of problems manifest themselves, which prove to be insurmountable in practical implementation.

This circumstance leads to the fact that developers abandon attempts to realize the advantages of recursive digital filters over FIR filters in terms of the amount of computing resources. To confirm this fact, we give an example. For implementation on programmable logic circuits (FPGAs), Altera Corporation offered developers a design tool such as digital filter compiler with infinite impulse response IIR Compilator. However, in 2003, Altera stopped supporting this product [7].

The reason for the difficulties in the synthesis of IIR digital filters with finite word length is the insufficient depth of the study of the fundamental features of computational processes in recursive digital filters, the lack of development tools that take into account these features.

In the series of publications, which include [8] - [11], a new approach to the synthesis of IIR digital filters with finite word length is proposed, in which attempts are made to overcome the mentioned difficulties of synthesis.

This paper is an analytical review of papers describing this new approach.

By the way, it makes sense to note the subtlety in the use of terminology related to IIR filters. It is believed that the terms recursive digital filter and the digital filter with infinite impulse response are equivalent. However, when the filter is implemented in fixed-point arithmetic, it is impossible to represent numbers whose absolute value is too small. Therefore, the length of the impulse response will be either finite (however greater than the filter order) or infinite. Nevertheless, this infinity will exist due to the presence of parasitic oscillations of the limit cycle.

Therefore, it appears that the term recursive filter is more accurate and will be used in this work. 


\section{APPROACHES TO THE SYNTHESIS OF RECURSIVE DIGITAL FILTERS WITH FINITE WORD LENGTH}

In the traditional approach to the synthesis of recursive filters, one can single out [4] - [6] such stages as functional synthesis, structural synthesis, parametric synthesis, quantization of coefficients.In functional synthesis, the transfer function (it's zeros and poles) is calculated. At structural synthesis stage, the block diagram is chosen. Parametric synthesis is devoted to the calculation of the coefficients of the selected structure without taking into account the finite word length.

The latter operation leads to the distortion of the exact value of the coefficients of the digital filter, to the distortion of the zeros and poles of the digital filter, to the distortion of the transfer function, frequency characteristics. Then they resort either to an increase in the bit width or to a change in the structural scheme. Despite the large number of publications describing the various structures, their use is limited by the unique method of calculating each structure and the extremely limited nomenclature of the structures offered in the available development systems.

Based on the studied number-theoretic nature of zeros and poles of digital filters with finite bit capacity, it is proposed to finally calculate the zeros and poles of the digital filter at the functional synthesis stage, taking into account the restrictions on the length of the discharge grid. The next stage of structural synthesis will not distort the results of functional synthesis.

Studies have shown the relationship between the structure of the digital filter and the number-theoretical nature of zeros and poles. It is proposed to generate structural schemes in accordance with this nature, based on the identified algebraic features of the matrix description of structures.

\section{THEORETICAL AND NUMERICAL ANALYSIS OF ZEROES AND POLES}

\section{A. Algebraic numbers}

It is known that if the coefficients of a polynomial

$$
\mathrm{P}(z)=\sum_{i=0}^{n} c_{i} z^{n-i}
$$

are elements of the set of rational numbers

$$
c_{i} \in Q \text {, }
$$

then the roots of this polynomial belong to the set of algebraic numbers

$$
z_{i} \in A
$$

For subsets of algebraic numbers, the expression

$$
Q=A_{1} \subset A_{2} \subset \ldots \subset A_{k} \subset \ldots \subset A_{n} \subset A .,
$$

where the indices $k$ of identifiers of subsets are the degrees of algebraic numbers (the degrees of the minimal or canonical polynomial of the elements of the subset $A_{k}$ ).
The maximum possible degree of algebraic numbers that are the roots of a polynomial $\mathrm{P}(z)$ is equal to the degree of the polynomial, but the maximum degree of $z_{i}$ may be less than the degree of the polynomial.

For example, the roots of a polynomial $P_{1}(z)=z^{4}+z^{3}+z^{2}+z+1$ are algebraic numbers of the fourth degree $z_{1,2,3,4}=\frac{1}{4}(\sqrt{5}-1 \pm j \sqrt{2} \sqrt{(\sqrt{5} \pm 5)})$. This polynomial cannot be represented as a product of two polynomials of the second degree with rational coefficients: $\mathrm{P}_{1}(z)=\left(z^{2}+0.5(1-\sqrt{5}) z+1\right)\left(z^{2}+0.5(1+\sqrt{5}) z+1\right)$.

At the same time, the degree of the roots of a polynomial is two:

$$
\begin{aligned}
& \mathrm{P}_{2}(z)=\left(\left(z+\frac{3}{2}-\frac{1}{2} \sqrt{5}\right)\left(z+\frac{3}{2}+\frac{1}{2} \sqrt{5}\right)\right) * \\
& *\left(\left(z-\frac{1}{2}-j \frac{\sqrt{3}}{2}\right)\left(z-\frac{1}{2}+j \frac{\sqrt{3}}{2}\right)\right)=\left(z^{2}+3 z+1\right)\left(z^{2}-z+1\right) .
\end{aligned}
$$

\section{B. The algebraic-numerical nature of the zeros and poles of practicable digital filters}

If you do not take into account the effects of finite word length, then the coefficients $a_{i}$ and $b_{i}$ of the transfer function

$$
\mathrm{H}(\mathrm{z})=\frac{\sum_{i=0}^{n} b_{i} z^{n-i}}{\sum_{i=0}^{n} a_{i} z^{n-i}},
$$

$a_{i} \in \mathrm{R}$, and $b_{i} \in \mathrm{R}$, the real and imaginary parts of zeros $\operatorname{Re} z_{z i} \in \mathrm{R}, \operatorname{Im} z_{z i} \in \mathrm{R}$ and poles $\operatorname{Re} z_{p i} \in \mathrm{R}, \operatorname{Im} z_{p i} \in \mathrm{R}$ are elements of the set of real numbers $(R)$.

All practicable digital filters are characterized by finite lengths of words, so the coefficients of the transfer function are elements of the subset $Q_{m}$ of the set of rational numbers $Q$. If the coefficients of the digital filter are represented by a binary additional code in the form with fixed point, then $\mathrm{m}$ is the length of the fractional part of the coefficients. In [13] - [15] it was shown that zeros and poles are elements of a subset of the set of algebraic numbers A.

\section{Topography of zeros and poles in the z-plane for the digital filters with quantized coefficients}

If the conditions $a_{i} \in \mathrm{R}$ and $a_{i} \in \mathrm{R}$ are satisfied, then any point of the z-plane can be a zero or a pole of the transfer function (5). In the case of quantization of the coefficients of the digital filter, only $z$-plane points whose coordinates are algebraic numbers can be zeros and poles. The degree of algebraic numbers in this case is determined 
by the structure of the digital filter and may be less than the order of the filter, as shown above [39], [40].

In [16], and [39], it was shown that for filters implemented in a direct and canonical structure, the degree of zeros and poles is equal to the filter order. For even-order filters implemented in a cascade structure, the degree of zeros and poles is two. For even-order filters implemented in a parallel structure, the degree of zeros is equal to the order of the filter, and the degree of poles is two.

The topography of zeros and poles of the digital filter in the z-plane is determined not only by their degree, but also by the bit fraction of the fractional part of the coefficients of the digital filter (coefficients of the minimal polynomial).

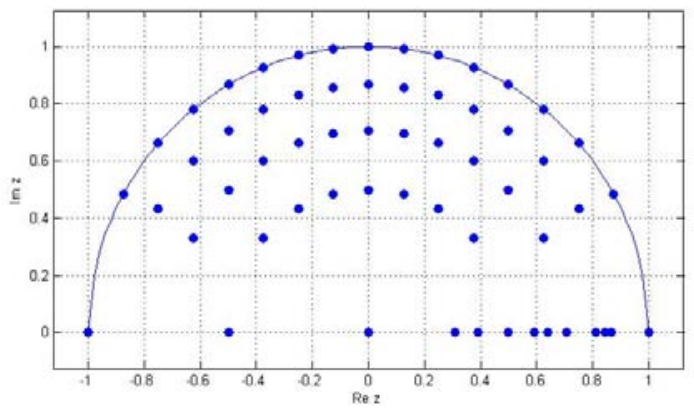

Fig. 1. Topography of second-degree algebraic numbers (length of the coefficient fractional part $m=2$ )

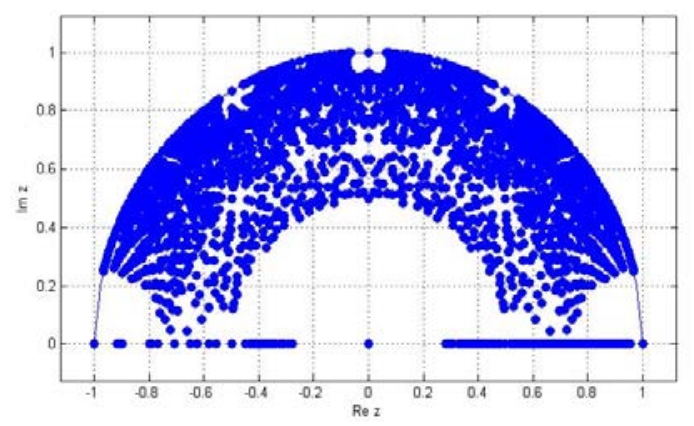

Fig. 2. Topography of the fourth-degree algebraic numbers (length of the fractional part of the coefficients $\mathbf{m}=2$ )

Figures 1 and 2 show all possible positions of algebraic numbers of the second and fourth degree with the fractional part of the coefficients $m=2$ inside the upper half of the unit circle of the z-plane.

For algebraic numbers of the second degree, their geometrical place in the z-plane is described in detail in [17]. Unfortunately, such a description for algebraic numbers of a higher degree could not be obtained. If in the first case the geometric place is a system of concentric circles with a definite center on the abscissa axis and a certain radius, then in the second case the shape of the curves is much more complicated.

If the coefficients of polynomials are coupled by additional equations, then several elements are excluded from the sets of possible values. As a result, the topography changes. This is described in [18].
D. Relationship between the z-plane and the space of coefficients of the minimal polynomial

As noted above, the topography of the roots of a minimal second-degree polynomial is well-studied [17]. As a result, you can search for zeros and poles directly in the $z$ plane. For algebraic numbers of a higher degree, analytical expressions are currently absent. However, in this case, an indirect approach can be used to search for parameters of digital filters. To the geometric locus of algebraic numbers of the corresponding degree, we put in correspondence the geometric locus of the coefficients of the minimal polynomial.

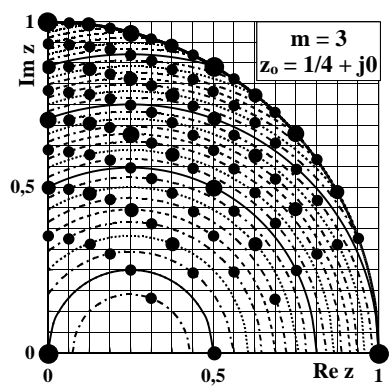

(a)

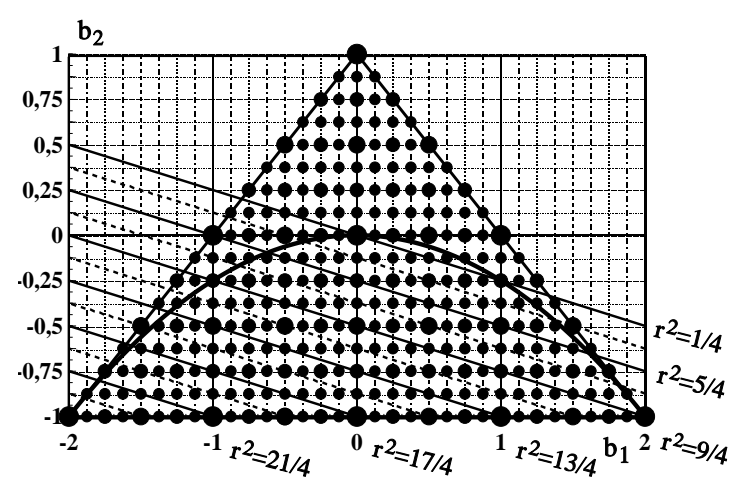

(b)

Fig. 3. Mapping of a system of circles onto a plane of coefficients for the second-degree algebraic numbers

Figure 3 shows (for algebraic numbers of the second degree with $m=3$ ) a map of a system of concentric circles with a center $z_{0}=0.25+j 0$ on a system of equidistant lines in the plane of coefficients of the minimal polynomial $z^{2}-b_{1} z-b_{2}$. The slope of straight lines is determined by the center of concentric circles:

$$
b_{2}=-z_{0} b_{1}+\left(z_{0}^{2}-r^{2}\right),
$$

where $r^{2}$ is the square of the radius [13], [14], [17].

For algebraic numbers of a higher degree, we operate with the values of the coefficients of the minimal polynomial. In this case, it is necessary to solve the problem of stability of the digital filter [14], [15], [19]. The poles of such digital filters must be inside the unit circle in the $z$ plane, excluding the unit circle, so you must resort to nu- 
merical methods for determining the roots of the polynomial.

\section{SYNTHESIS OF DigITAL FILTERS AT THE FUNCTIONAL LEVEL}

In view of the above, it is advisable to use the following procedure for synthesizing digital filters at the functional level.

1. Execution of the standard procedure of approximation of the frequency response, as a result of which a set of zeros and poles is calculated:

$$
z_{z i} \in \mathrm{C}=\mathrm{R}^{2}, z_{p i} \in \mathrm{C}=\mathrm{R}^{2}, i=1, \ldots, n .
$$

2. The choice of the initial value of the degree of zeros and poles

$$
A l g P w_{z}=P w_{z 0}, A l g P w_{p}=P w_{p 0} .
$$

For even $n$, it is natural to choose $P w_{z 0}=P w_{p 0}=2$.

3. The choice of the initial values of the bitness of the fractional part of the coefficients of the minimum polynomials of degree $A \lg P w_{z}$ for zeros $\left(m_{\mathrm{z}}\right)$ and $A l g P w_{p}$ for poles $\left(m_{\mathrm{p}}\right)$.

4. Determination of the initial value of zeros with parameters $\left\{A \lg P w_{z}, m_{z}\right\}$ and poles $\left\{A \lg P w_{p}, m_{p}\right\}$ (for complex roots, it is necessary to provide complex conjugacy), or the initial value of the coefficients of the corresponding minimal polynomials.

5. Execution of the search procedure on the sets of zeros and poles or on the sets of coefficients of the corresponding minimal polynomials.

5.1. When fulfilling the requirements for a digital filter, complete the procedure. tion.

5.2. The decision to continue the search or its termina-

6 . The decision to increase the length of the fractional part of the coefficients with the transition to paragraph 7 or to refuse to further increase these parameters with the transition to paragraph 9.

\section{Increase $m_{z}$ and/or $m_{p}$. \\ 8. Return to paragraph 6.}

9. The decision to increase the degree of zeros and poles with the transition to paragraph 10 or to refuse further increasing these parameters with the transition to paragraph 12.

10. Increasing the degree of zeros and/or poles.

\section{Return to paragraph 6.}

12. Deciding to change the requirements for the digital filter.

13. Return to paragraph 1.

\section{THE DESCRIPTION OF THE STRUCTURE OF THE}

\section{DigITAL FILTER WITH THE TOPOLOGICAL MATRIX}

As a mathematical model of the digital filter block diagram, it is advisable to use a matrix of transfer coefficients between the nodes of the block diagram [21]. We will call such a matrix topological. It most adequately describes the structural scheme and its properties, including numbertheoretic [14], [15].

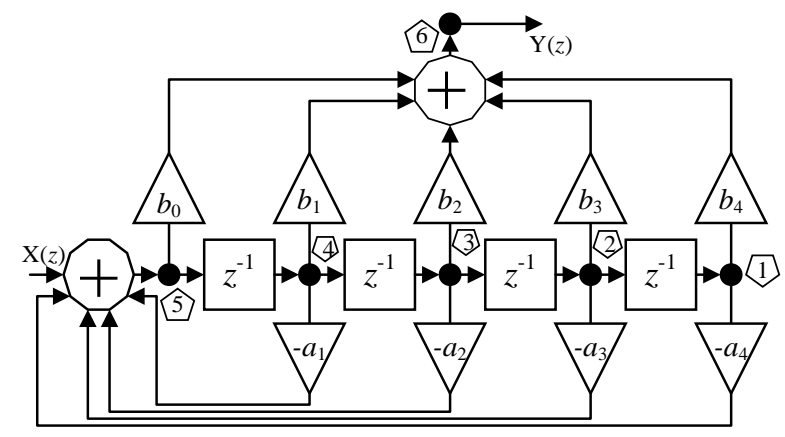

Fig. 4. The canonical form of the fourth order recursive filter

For example, the block diagram presented in Fig. 4, is described by the following topological matrix (9)

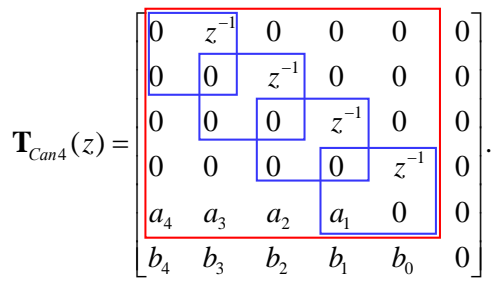

For completeness, you must also specify the number of input and output nodes. The canonical form of a topological matrix is considered to be one in which all the elements $Z^{-1}$ corresponding to the delay blocks are located above the main diagonal, and the elements corresponding to the multiplication blocks are located below the main diagonal. If the circuit is physically realizable (computable), i.e. does not contain closed contours without delay elements, then there is a numbering of nodes, in which the topological matrix is canonical [21].

If the vector $\mathbf{Y}(z)$ is a vector of $z$-transformations of sequences of samples calculated at the nodes of the structural scheme, then we can write the equation

$$
\mathbf{Y}(z)=\mathbf{T}(z) \mathbf{Y}(z)+\mathbf{I} X(z),
$$

where $\mathbf{I}$ is a vector, all elements of which are zero, except for the element with the number equal to the number of the input element. This item is equal to 1. Equation (10) can be converted to

$$
\mathbf{Y}(z)=(\mathbf{E}-\mathbf{T}(z))^{-1} \mathbf{I} X(z)
$$


where $\mathbf{E}$ is the identity matrix. Matrix

$$
\mathbf{H}(z)=(\mathbf{E}-\mathbf{T}(z))^{-1}
$$

- is the matrix of transfer functions $\mathrm{H}_{i j}(\mathrm{z})(i, j$ - numbers of the output and input nodes, respectively).

\section{THE RELATIONSHIP BETWEEN THE THIN}

STRUCTURE OF THE TOPOLOGICAL MATRIX AND NUMBER-

THEORETICAL PROPERTIES OF ZEROES AND NODES

In [14], [15], [22], [23] it was shown that the degree of poles is determined by the structure of the canonical form of the topological matrix for digital filters, the order of which is equal to the number of delay blocks. In such a matrix, square submatrices can be distinguished, the elements of the main diagonals of which are the elements of the main diagonal of the topological matrix, the elements $z^{-1}$ being the last elements of the first row of the sub-matrix. Clusters can be formed from submatrices. Any submatrix included in this cluster has common elements with at least one submatrix entering this cluster and has no common elements with submatrices belonging to other clusters. If a cluster combines $r$ submatrices, then $r$ poles of $r$-th degree correspond to this cluster. For example [38], in the topological matrix (9) there is one cluster that combines four submatrices. Therefore, the degree of all poles of the canonical form of a fourth-order recursive digital filter is four. And the degree of poles of the cascade structure of a fourth-degree digital filter (Fig. 5) is two. The topological matrix of such a structure has the form

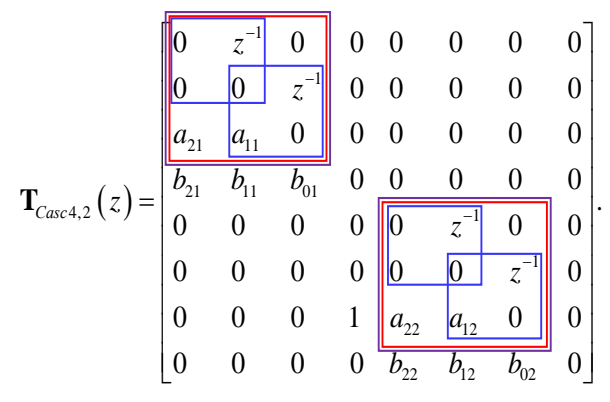

Unfortunately, it is not possible to establish a connection between the structure of the topological matrix and the degree of zeros. So far, the following approach is proposed to determine the degree of zeros for a particular structure. If a polynomial with rational coefficients in the numerator of the transfer function can have an algebraic number of $r$ th degree as its root, then the corresponding zero is $r$-th degree zero. However, it is difficult to solve this problem. It is easier to use the following approach.

If an algebraic number of $r$-th degree, being the root of the polynomial of the numerator of the transfer function, leads to the fact that the coefficients of this polynomial are not rational numbers, then the zeros of such a digital filter cannot have $r$-th degree. The problem is to determine the maximum degree of zeros for this structure.

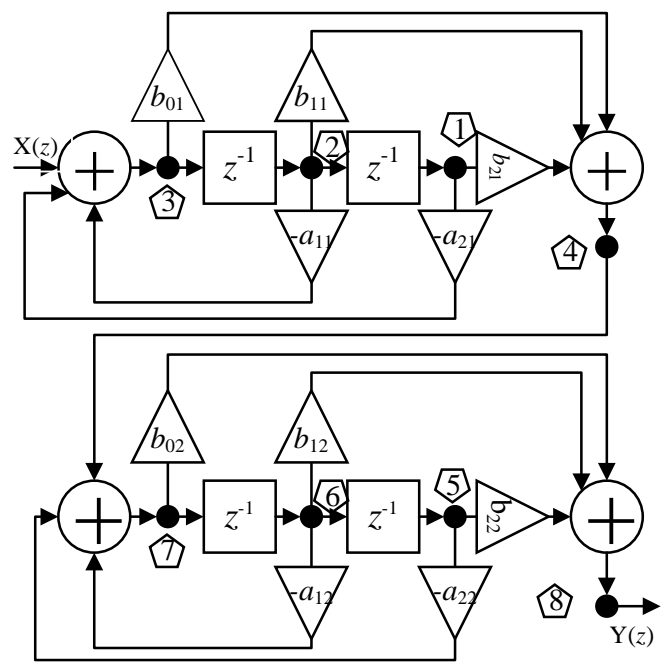

Fig. 5. Cascade form of fourth order IIR filter

\section{GENERATION OF DigitAl FILTER STRUCTURES}

In [14], [15], [24] - [26], it was shown that by generating the canonical forms of a topological matrix of order $N$ with all possible admissible coefficients and specifying the numbers of the input (inp) and output (out) nodes, it is possible to obtain all the structures of physically realizable digital filters with $N$ nodes.As an example, consider the option for which $N=5$, inp $=3$, out $=4$ :

$$
\mathbf{T}\left(z^{-1}\right)=\left[\begin{array}{ccccc}
0 & z^{-1} & 0 & 0 & 0 \\
c_{21} & 0 & 0 & 0 & z^{-1} \\
c_{31} & c_{32} & 0 & 0 & 0 \\
c_{41} & c_{42} & c_{43} & 0 & 0 \\
c_{51} & c_{52} & c_{53} & c_{54} & 0
\end{array}\right] .
$$

This matrix corresponds to the digital filter, a block diagram of which is shown in Fig. 6.

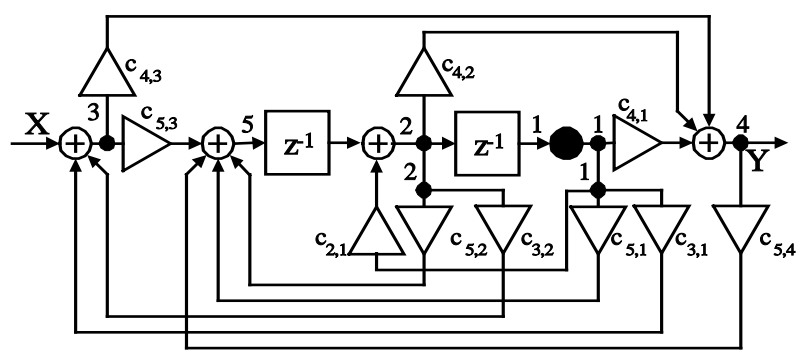

Fig. 6. Example of generated digital filter structure

The number of multiplication blocks in the generated structures exceeds the number of degrees of freedom (the number of transfer function coefficients). In [27] - [29], methods of synthesizing new canonical second order structures are presented, based on the generation of all possible structures with a given number of nodes, choosing a set consisting of five coefficients, zeroing the remaining coefficients, discarding trivial structures. 
In [31], [32] a different approach was applied. Redundancy is used to reduce the bitness of the coefficients (an increased number of multiplication blocks is exchanged for a decrease in the word length).

We will demonstrate this approach on the example of the redundant structure of Fig. 7. Fig. 8 shows the transformed structure without multipliers.

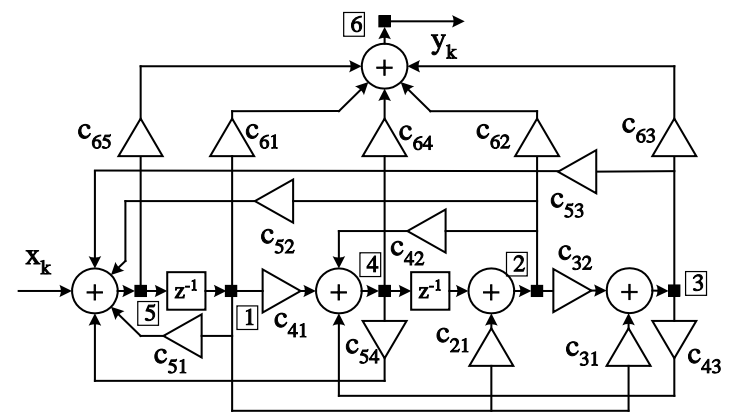

Fig. 7. Structure with excess multipliers

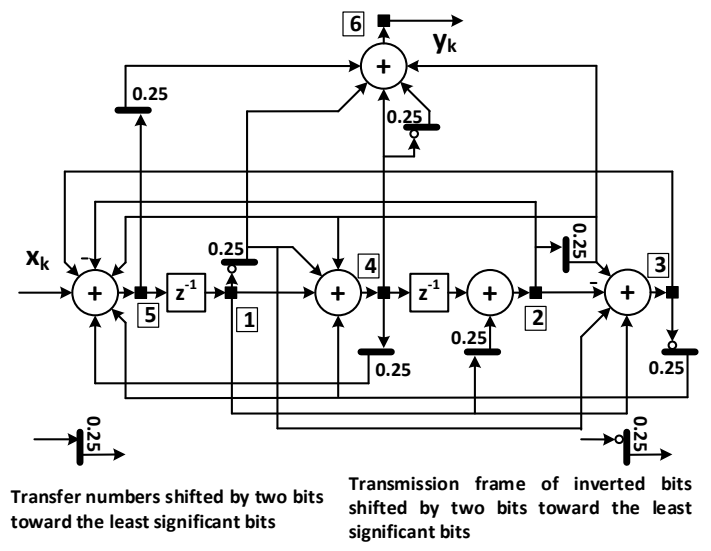

Fig. 8. A multiplierless structure equivalent to the structure in Fig. 7

To estimate the level of rounding noise, a representation of the structure in the state space is usually used. In [33] - [35], rounding noises of the results of arithmetic operations in the generated structure are estimated by a topological matrix.

In [36], [37] a method for estimating the structural complexity of the generated structures is presented.

\section{CONCLUSION}

An approach to the synthesis of recursive digital filters with finite word length is proposed, taking into account the algebraic-numeric nature of zeros and poles, the algebraic properties of the matrix structure description. The approach allows one to calculate zeros and poles, taking into account the restrictions on the length of the discharge grid, even before the stage of structural synthesis, and to generate the structure of the digital filter taking into account the number-theoretic properties of the transfer function. Further research involves the development of effective means of functional and structural synthesis in the framework of the described approach.

\section{SUPPORT}

This work was supported by the Russian Foundation for Basic Research - grant 18-07-00986a.

\section{REFERENCES}

[1] Butterweck H.J., Ritzerfeld J.H.F., Werter M.J. Finite wordlength effects in digital filters: a review // EUT report, E, Fac. of Electrical Engineering. V. 88-E-205. Eindhoven: EindhovenUniversity of Technology. 1988.

[2] Gevers M., Li G. Parametrizations in Control, Estimation and Filtering Problems: Accuracy Aspects, Communications and Control Engineering. London: Springer, 1993.

[3] Bomar B.W. Finite Wordlength Effects / Digital Signal Processing Handbook / Ed. V. K. Madisetti and D. B. Williams. Boca Raton: CRC Press LLC. 1999.

[4] Losada R.A. Digital Filters with MATLAB ${ }^{\circledR}$. The MathWorks, Inc, 2008.

[5] Signal Processing Toolbox ${ }^{\mathrm{TM}}$. User's Guide. The MathWorks, Inc. 2017.

[6] DSP System Toolbox ${ }^{\mathrm{TM}}$. Getting Started Guide. The MathWorks, Inc. 2017.

[7] Does Altera support IIR compiler? URL: https://www.altera.com/support/supportresources/knowledge-base/solutions/rd04072011_238.html (access date: 11.04.2018).

[8] Lesnikov V., Chastikov A., Naumovich T., Armishev S. A new paradigm in design of IIR digital filters // IEEE EastWest Design and Test Symposium (EWDTS 2010). St. Petersburg. 17-20 Sept. 2010. P. 282-285.

[9] Lesnikov V., Chastikov A., Naumovich T., Armishev S. Implementation of a new paradigm in design of IIR digital filters // IEEE East-West Design and Test Symposium (EWDTS 2010). St. Petersburg. 17-20 Sept. 2010. P. 156159. DOI: 10.1109/EWDTS.2010.5742051.

[10] Lesnikov V., Naumovich T., ChastikovA. Novyj podhod k proektirovaniyu rekursivnyh cifrovyh fil'trov // Problemy razrabotki perspektivnyh mikro- i nanoehlektronnyh sistem - 2010. Sb. trudov / pod obshch. red. akademika A.L. Stempkovskogo. M.: IPPM RAN, 2010. S. 466-471. URL: http://www.mes-conference.ru/data/year2010/papers/m106-57111.pdf (access data 11.04.2018). In Russian.

[11] Hilbert D. The Theory of Algebraic Number Fields. Berlin - Heidelberg - New York: Springer - Verlag, 1998.

[12] Ireland K., Rosen M. A classical introduction to modern number theory, 2nd ed., New York: Springer-Verlag, 1990.

[13] Lesnikov V.A., Naumovich T.V., Reshetnikov S.M., Chastikov A.V. Algebraiko-chislovaya priroda nulej i polyusov rekursivnyh cifrovyh fil'trov (Number-algebraic nature of zeros and poles of recursive digital filters) // Global'nyj nauchnyj potencial. 2011. № 9. S. 52 - 55. In Russian.

[14] Lesnikov V.A., Naumovich T.V. Strukturnyj sintez cifrovyh fil'trov (Structural synthesis of digital filters). Kirov: Vyatskij gosudarstvennyj universitet, 2006. - 196 s. In Russian.

[15] Lesnikov V.A., Naumovich T.V. Strukturnyj sintez cifrovyh fil'trov (Structural synthesis of digital filters). Kirov: O-kratkoe, 2008. - 160 s. In Russian. 
[16] Lesnikov V.A., Naumovich T.V., Chastikov A.V. Razbienie mnozhestva strukturnyh skhem cifrovyh fil'trov na klassy ehkvivalentnosti po teoretiko-chislovym svojstvam (Splitting the set of digital filter structure diagrams into equivalence classes by number-theoretic properties) // DSPA: Voprosy primeneniya cifrovoj obrabotki signalov. 2018. T. 1. № 1. S. 98-100. In Russian.

[17] Lesnikov V., Naumovich T., Chastikov A. Topography of z-plane which is discretized due to quantization of coefficients of digital biquad filters // 2016 International Siberian Conference on Control and Communications (SIBCON2016), Moscow, Russia, 12-14 May 2016. DOI: 10.1109/SIBCON.2016.7491812.

[18] Lesnikov V.A., Naumovich T.V., Chastikov A.V. Cifrovye fil'try vtorogo poryadka s nekanonicheskoj topografiej polyusov v z-ploskosti(Second-order digital filters with noncanonical poles topography in the z-plane) // Problemy razrabotki perspektivnyh mikro- i nanoehlektronnyh sistem 2010. Sb. trudov / pod obshch. red. akademika A.L. Stempkovskogo. M.: IPPM RAN, 2014. № 4. S. 129-132. URL: http://www.mesconference.ru/data/year2014/pdf/D143.pdf. In Russian.

[19] Lesnikov V., Naumovich T., Chastikov A. The formulation of criteria of BIBO stability of 3rd-order IIR digital filters in space of coefficients of a denominator of transfer function // IEEE East-West Design and Test Symposium (EWDTS 2014), Kiev, Ukraine, 26-29 Sept. 2014. 3 p. DOI: 10.1109/EWDTS.2014.7027080.

[20] Lesnikov V.A., Naumovich T.V., Chastikov A.V. Formulirovka kriteriev ustojchivosti cifrovyh fil'trov tret'ego poryadka s beskonechnoj impul'snoj harakteristikoj $\mathrm{v}$ prostranstve koefficientov znamenatelya peredatochnoj funkcii // Problemy razrabotki perspektivnyh mikro- i nanoehlektronnyh sistem - 2014. Sb. trudov / pod obshch. red. akademika A.L. Stempkovskogo. M.: IPPM RAN, 2014. № 4. S. 141-146. URL: http://www.mesconference.ru/data/year2014/pdf/D132.pdf.In Russian.

[21] Crochier R. E., Oppenheim A. V. Analysis of linear digital circuits // Proceedings of IEEE. 1975. Vol. 63. № 4. P. 581 - 595. DOI: 10.1109/PROC.1975.9793.

[22] V.A. Lesnikov, T.V. Naumovich, S.M. Reshetnikov, A.V. Chastikov. Vzaimosvyaz' teoretiko-chislovoj prirody polyusov i struktury topologicheskoj matricy rekursivnogo cifrovogo fil'tra (Interrelation of the number-theoretic nature of poles and the structure of the topological matrix of a recursive digital filter) // Perspektivy nauki. 2011. № 11 (26). S. 112-115. In Russian.

[23] Lesnikov V., Naumovich T., Chastikov A. Classification of structures of IIR digital filters // IEEE East-West Design and Test Symposium (EWDTS 2015), Batumi, Georgia, 2629 Sept. 2015. 5 p. DOI: 10.1109/EWDTS.2015.7493154.

[24] Lesnikov V.A., Naumovich T.V. Generaciya i numeraciya struktur pri strukturnom sinteze rekursivnyh cifrovyh fil'trov (Generation and numbering of structures in the structural synthesis of recursive digital filters) // Sb. trudov 6-j mezhdunarodnoj nauchno-tekhnicheskoj konferencii "Radiolokaciya, navigaciya, svyaz"'. Voronezh, 2000. T. 3. S. 1858 - 1868. In Russian.

[25] Lesnikov V. A., Naumovich T.V. Generaciya struktur cifrovyh fil'trov (Generating Digital Filter Structures)// Doklady 3-j Mezhdunarodnoj konferencii "Cifrovaya obrabotka signalov i ee primenenie”. Doklady-1. M., 2001. S. 135-139. In Russian.
[26] Lesnikov V., Naumovich T., Chastikov A. Generation and decomposition of digital filter topology // IEEE East-West Design and Test Symposium (EWDTS 2017), Novi Sad, Serbia, 29 Sept.-2 Oct. 2017. 4 p. DOI: 10.1109/EWDTS.2017.8110161.

[27] Lesnikov V.A., Naumovich T.V., Chastikov A.V. Synthesis of new canonic structures for a second-order IIR digital filters // IEEE EUROCON 2009, 18-23 May 2009. St. Petersburg, Russia. P. 1328 - 1331. DOI: 10.1109/EURCON.2009.5167811.

[28] Lesnikov V., Naumovich T., Chastikov A., S. Armishev.A generation of canonical forms for design of IIR digital filters // IEEE East-West Design and Test Symposium (EWDTS 2011), Sevastopol, Ukraine, 9-12 Sept. 2011. P. 221 - 224. DOI: 10.1109/EWDTS.2011.6116600.

[29] Lesnikov V.A., Naumovich T.V., Chastikov A.V. Cintez novyh kanonicheskih struktur rekursivnyh cifrovyh fil'trov vtorogo poryadka (Synthesis of new canonical structures of recursive digital filters of the second order) // Infokommunikacionnye tekhnologii. 2009. T. 7. № 1. S. 17-20. In Russian.

[30] Lesnikov V.A., Naumovich T.V., Chastikov A.V. Usovershenstvovannaya metodika sinteza kanonicheskih struktur rekursivnyh cifrovyh fil'trov (An improved technique for synthesizing the canonical structures of recursive digital filters) // DSPA: Voprosy primeneniya cifrovoj obrabotki signalov. 2011. T. 1. № 1. S. 130-133.

[31] Lesnikov V., Naumovich T., Chastikov A. The use of redundancy in the structural synthesis of IIR digital filters // IEEE East-West Design and Test Symposium (EWDTS 2016), Yerevan, Armenia, 14-17 Oct. 2016. 3 p. DOI: 10.1109/EWDTS.2016.7807645.

[32] Lesnikov V.A., Naumovich T.V., Chastikov A.V. Ispol'zovanie izbytochnosti v strukturnom sinteze cifrovyh fil'trov (The use of redundancy in the structural synthesis of digital filters) // Advanced Science. 2017. № 1. S. 29 - 38.

[33] Lesnikov V.A., Naumovich T.V., Chastikov A.V. Universal'naya metodika ocenivaniya shumov okrugleniya v rekursivnyh cifrovyh fil'trah, opisyvaemyh topologicheskimi matricami (A universal method for estimating rounding noise in recursive digital filters described by topological matrices)// Problemy razrabotki perspektivnyh mikronanoehlektronnyh sistem (MES). 2012. № 1. S. 561-564.

[34] Lesnikov V.A., Naumovich T.V., Chastikov A.V. Ocenivanie urovnya shumov okrugleniya v cifrovyh fil'trah s proizvol'noj strukturnoj skhemoj (Estimation of rounding noise level in digital filters with arbitrary block diagram) // DSPA: Voprosy primeneniya cifrovoj obrabotki signalov. 2012. T. 1. № 1. S. 98-100. In Russian.

[35] Lesnikov V., Naumovich T., Chastikov A., Armishev S. Universal technique of the analysis of round-off noise in digital filters with arbitrary structure described by topological matrixes// IEEE East-West Design and Test Symposium (EWDTS 2013), Rostov-on-Don, Russia, 27-30 Sept. 2013. 4 p. DOI: 10.1109/EWDTS.2013.6673199.

[36] Lesnikov V., Naumovich T., Chastikov A., Armishev S. Estimation of structural complexity of IIR digital filters // IEEE East-West Design and Test Symposium (EWDTS 2013), Rostov-on-Don, Russia, 27-30 Sept. 2013. 5 p. DOI: 10.1109/EWDTS.2013.6673143.

[37] Lesnikov V.A., Naumovich T.V., Chastikov A.V. Ocenivanie strukturnoj slozhnosti rekursivnyh cifrovyh fil'trov (Evaluation of the structural complexity of recursive 
digital filters) // Izvestiya YUFU. Tekhnicheskie nauki. 2013. № 2 (139). S. 89-93.

[38] Lesnikov V., Naumovich T., Chastikov A. Sensitivity Analysis of the Equivalent Direct Form of IIR Digital Filters // IEEE East-West Design and Test Symposium (EWDTS 2018), Kazan, Russia, 14-17 Sept. 2018. 6 p. DOI: 10.1109/EWDTS.2018.8524772.

[39] Lesnikov V., Naumovich T., Chastikov A. Numbertheoretical analysis of the structures of classical IIR digital filters $/ / 7^{\text {th }}$ Mediterranean Conference on Embedded Computing (MECO), Budva, Montenegro, 10-14 June 2018. 4 p. DOI: 10.1109/MECO.2018.8406099.

[40] Lesnikov V., Naumovich T., Chastikov A. The sampling of the z-plane due to the quantization of the digital filter coefficients $/ / 7^{\text {th }}$ Mediterranean Conference on Embedded Computing (MECO), Budva, Montenegro, 10-14 June 2018. 4 p. DOI: 10.1109/MECO.2018.8405962 